\title{
Retroperitoneal Schwannoma in the Renal Hilum: A Case Report
}

\author{
Yohei Kumano $^{\mathrm{a}}$ Takashi Kawahara ${ }^{\mathrm{a}, \mathrm{c}}$ Sawako Chiba ${ }^{\mathrm{b}}$ Yoko Maeda ${ }^{\mathrm{a}}$ \\ Mari Ohtaka $^{a}$ Takuya Kondo ${ }^{a}$ Taku Mochizuki ${ }^{a}$ Yusuke Hattori ${ }^{a}$ Jun- \\ Ichi Teranishi $^{a}$ Yasuhide Miyoshi ${ }^{a}$ Yasushi Yumura ${ }^{a}$ Yoshiaki Inayama $^{b}$ \\ Masahiro Yao ${ }^{c}$ Hiroji Uemura ${ }^{a}$ \\ Departments of a Urology and Renal Transplantation and ${ }^{b}$ Diagnostic Pathology, \\ Yokohama City University Medical Center, and ${ }^{C}$ Department of Urology, Yokohama City \\ University Graduate School of Medicine, Yokohama, Japan
}

\section{Key Words}

Schwannoma $\cdot$ Retroperitoneal tumor $\cdot$ Renal hilum

\section{Abstract}

A 73-year-old male was referred to our department for further treatment of a right retroperitoneal tumor. Contrast CT showed a tumor mass measuring $33 \times 26 \mathrm{~mm}$ in size with poor contrast enhancement. Because we were unable to rule out tumor malignancy, we planned an operation. The tumor was easily separated and removed without nephrectomy. Histological study revealed a schwannoma. It is rare for this kind of tumor to arise from the retroperitoneum (approximately $0.7 \%$ of all cases), in particular at the renal hilum. We herein report a rare case of retroperitoneal schwannoma arising from the renal hilum.

\section{Introduction}

Schwannomas are derived from Schwann cells on the peripheral nervous system and appear most commonly in the head, neck and limbs [1]. Previous reports of schwannomas arising from the retroperitoneum have been reported; however, they are extremely rare [2]. We herein report a rare case of retroperitoneal schwannoma arising from the renal hilum. 
Kumano et al.: Retroperitoneal Schwannoma in the Renal Hilum: A Case Report

\section{Case Presentation}

A 73-year-old male was referred to our department for further examination of a right retroperitoneal tumor in the renal hilum. There were no physical findings in particular. On abdominal CT and MRI, there was a tumor in the right hilum of the kidney, and it was well defined. Laboratory examination showed that only noradrenaline was slightly elevated at $809 \mathrm{ng} / \mathrm{dl}$. Therefore, we continued to follow the patient. Due to the gradually increasing size of the tumor, we could not rule out malignancy. Thus, we planned tumor resection with nephrectomy. Because there was no adhesion or invasion around the tissue, we performed complete resection. The histological diagnosis was schwannoma. The tumor has not recurred for 5 months after resection.

\section{Laboratory Data at the Time of Admission}

Hematological biochemistry data showed almost no abnormal findings. The hormonal values were as follows: noradrenaline $809 \mathrm{ng} / \mathrm{dl}$, adrenaline $46.0 \mathrm{pg} / \mathrm{dl}$, dopamine $29 \mathrm{pg} / \mathrm{dl}$, cortisol $13.2 \mu \mathrm{g} / \mathrm{dl}$, ACTH $52.7 \mathrm{pg} / \mathrm{dl}$, aldosterone $78.5 \mathrm{pg} / \mathrm{dl}, 11$-hydroxycorticosteroids 18.1 $\mathrm{pg} / \mathrm{dl}$, and vanillylmandelic acid $9.5 \mathrm{ng} / \mathrm{ml}$. On urinalysis, $\mathrm{pH}$ was 7.5 , RBC $0-1 /$ high power filed, WBC 0-1/high power field, protein (-), and glucose (-).

\section{Imaging Finings}

CT and MRI showed a mass measuring $4.5 \times 4.0 \mathrm{~cm}$ in size in the renal hilum (fig. 1). Contrast CT showed that the tumor was poorly enhanced, whereas MRI showed that the inside was uniform on the T1-weighted image; however, there was heterogeneous contrast on the T2-weighted image. No obvious distant and local lymphoid metastasis was detected by bone scintigraphy, MRI, or CT.

\section{Operative Procedure}

We planned radical nephrectomy with complete tumor resection. As the tumor was surrounded by two renal arteries, a reverse L-shaped incision was made and the transperitoneal approach was performed. When we approached the target tumor, the tumor was capsuled, and the margin between the renal hilum and the tumor was easily recognized. Though the tumor was fed by some of the small vessels, the tumor was successfully resected without nephrectomy (fig. 2).

\section{Pathological Findings}

The resected tumor measured $3.5 \times 2.5 \times 1.5 \mathrm{~cm}$ in size and was encapsulated. On cut section, the tumor had a yellow-tinted pink appearance with secondary degenerative changes, such as cystification and hemorrhage (fig. 3a). Microscopically, it was composed of spindle or oval cells with two distinct histological patterns: areas of compact, elongated cells with occasional nuclear palisading (Antoni A) and less cellular, loosely textured tumor areas (Antoni B; fig. 3b, c). According to these histological findings, the tumor was diagnosed as a schwannoma in the renal hilum.

\section{Discussion}

Schwannomas arise frequently in the head and neck (44.9\%) and the limbs (32.6\%). It is rare for a schwannoma to arise at the retroperitoneum (approximately 0.7-3\%) [3-7], and reports of schwannomas arising at the hilum are rare [2]. The behavior of a schwannoma 
Kumano et al.: Retroperitoneal Schwannoma in the Renal Hilum: A Case Report

appears to be silent, asymptomatic, and slow-growing, regardless of whether it is benign or malignant.

The basic treatment for a schwannoma is tumor removal by operation because the effect of chemotherapy and radiation is poor. The prognosis is good; however, recurrence is possible, and therefore, postoperative follow-up is necessary. In this case, we suspected that the tumor was benign; however, on preoperative examination, we could not completely rule out malignancy.

Due to the development and widespread use of laparoscopy, some cases have reported the successful removal of a retroperitoneal schwannoma using laparoscopic procedures [8]. In the present case, the tumor was pressing on the inferior vena cava and right renal arteries and veins. Furthermore, it was surrounded by two renal arteries. Thus, we initially planned transperitoneal surgery with nephrectomy. Hung et al. [1] reported that radical nephrectomy is recommended due to the difficulty of determining the preoperative diagnosis and the possibility of a malignant schwannoma. When we approached the tumor, it was encapsulated and did not show adhesion or invasion to the surrounding tissue; therefore, we removed the tumor without nephrectomy.

We herein report a rare case of retroperitoneal schwannoma arising from the renal hilum.

\section{Acknowledgement}

Grants from the Uehara Memorial Foundation, the Tokyo Biochemical Research Foundation, the Japanese Foundation for Research and Promotion of Endoscopy, the Yokohama Foundation for Advancement of Medical Science, and an International Exchange Grant from Kato Memorial Bioscience Foundation were provided to T.K. No grant numbers were applied.

\section{Statement of Ethics}

The authors have no ethical conflicts to disclose.

\section{Disclosure Statement}

The authors declare no conflicts of interest.

\section{References}

1 Hung SF, Chung SD, Lai MK, Chueh SC, Yu HJ: Renal schwannoma: case report and literature review. Urology 2008;72:716.e3-e6.

2 Iwasaki M, Nagashima M, Nagashima Y, Udagawa K: A case of schwannoma in the renal hilum. Hinyokika Kiyo 2013;59:423-426.

-3 Das Gupta TK, Brasfield RD, Strong EW, Hajdu SI: Benign solitary schwannomas (neurilemomas). Cancer 1969;24:355-366.

4 Alvarado-Cabrero I, Folpe AL, Srigley JR, Gaudin P, Philip AT, Reuter VE, et al: Intrarenal schwannoma: a report of four cases including three cellular variants. Mod Pathol 2000;13:851-856.

5 Ma KF, Tse CH, Tsui MS: Neurilemmoma of kidney - a rare occurrence. Histopathology 1990;17:378-380.

6 Gobbo S, Eble JN, Huang J, Grignon DJ, Wang M, Martignoni G, et al: Schwannoma of the kidney. Mod Pathol 2008;21:779-783. 
Kumano et al.: Retroperitoneal Schwannoma in the Renal Hilum: A Case Report

7 Singer AJ, Anders KH: Neurilemmoma of the kidney. Urology 1996;47:575-581.

8 Imao T, Seki M, Amano T, Takemae K: Laparoscopic resection of retroperitoneal schwannoma: report of three cases and review of 22 cases in Japanese literature. Hinyokika Kiyo 2011;57:491-495.
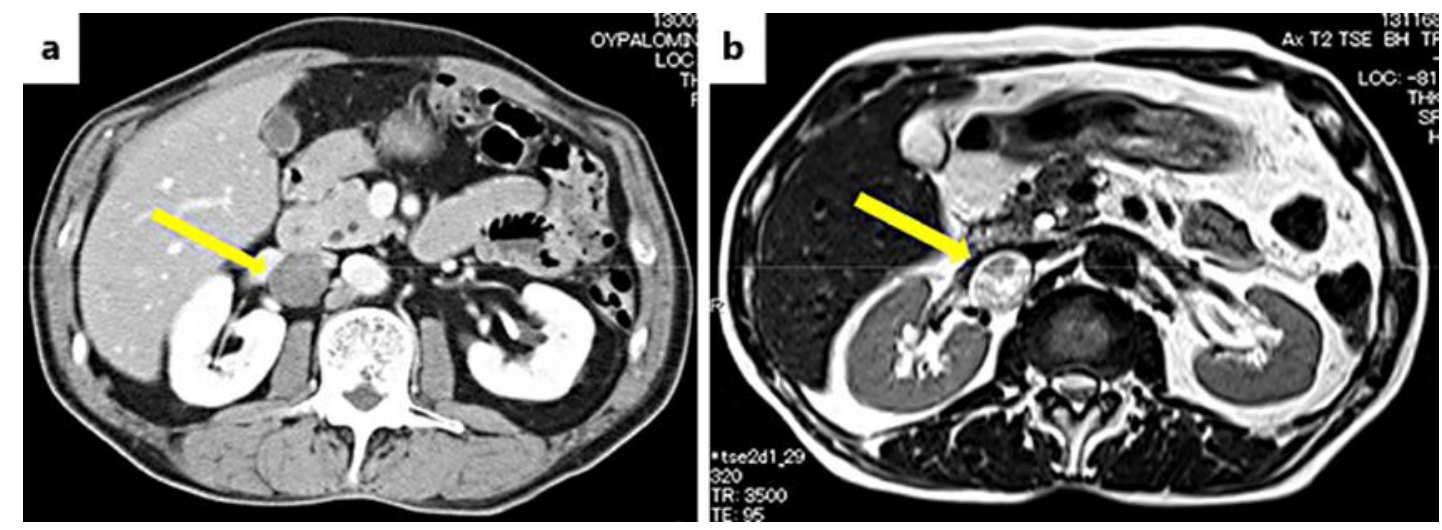

Fig. 1. a Contrast-enhanced CT. b T2-weighted MRI.
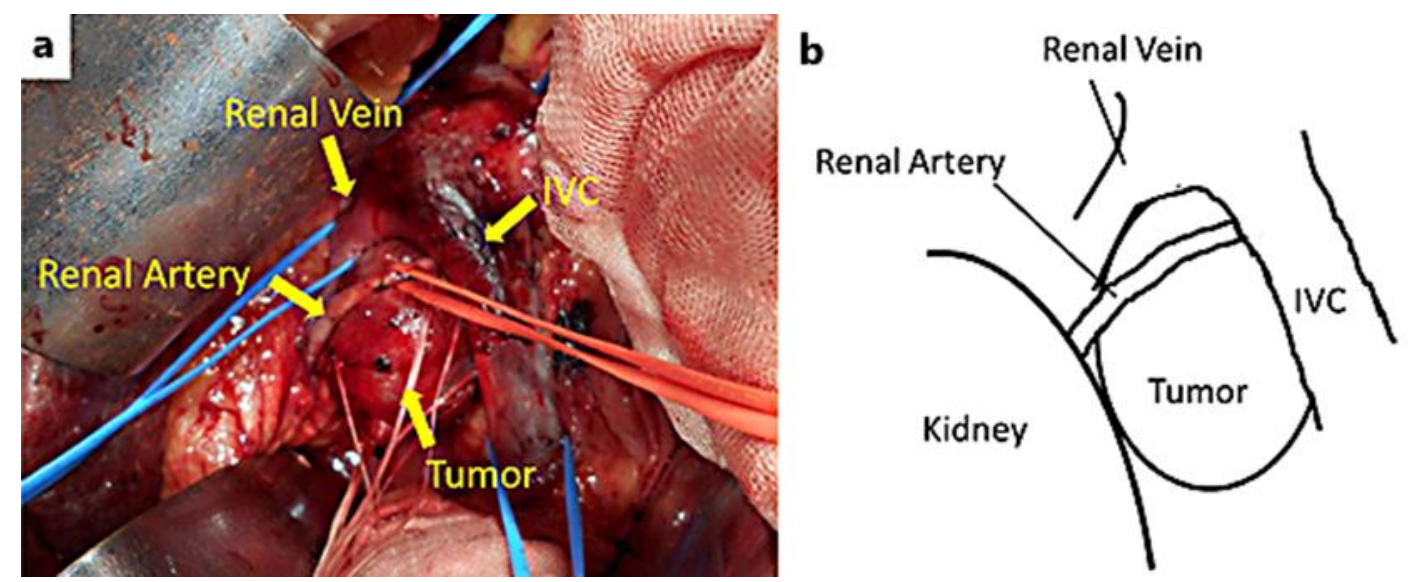

Fig. 2. Intraoperative image (a) and schematic illustration (b). IVC = Inferior vena cava. 


\section{Case Reports in Oncology}

\begin{tabular}{l|l}
\hline Case Rep Oncol 2015;8:394-398 \\
\hline DOI: 10.1159/000440612 & $\begin{array}{l}\text { (c) 2015 The Author(s). Published by S. Karger AG, Basel } \\
\text { www.karger.com/cro }\end{array}$ \\
\hline
\end{tabular}

Kumano et al.: Retroperitoneal Schwannoma in the Renal Hilum: A Case Report
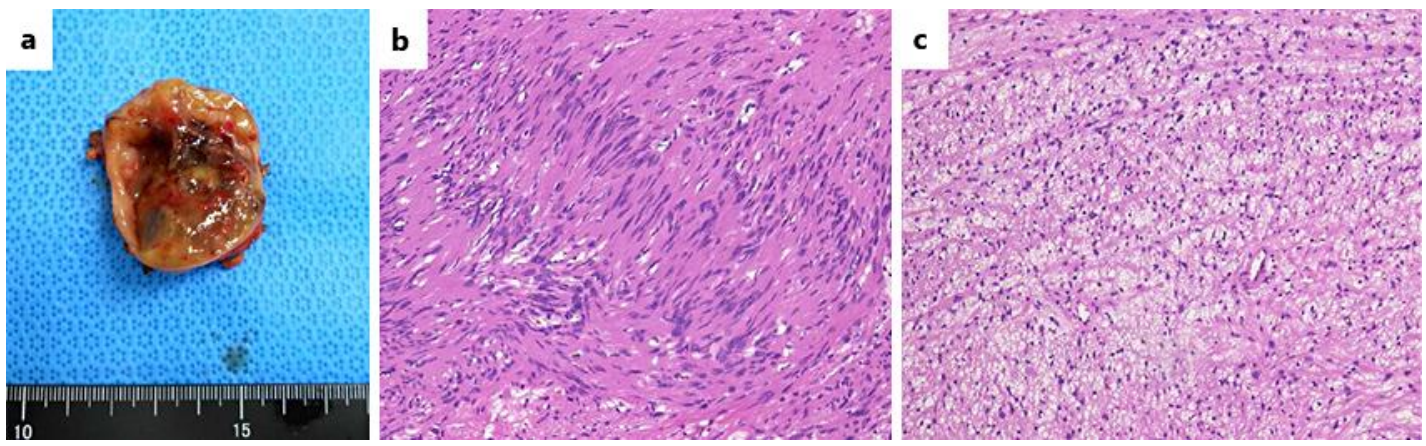

Fig. 3. a Surgical specimen. The cut surface of the tumor shows cystic change and hemorrhage. b, c The histological features of the tumor show a biphasic pattern with cellular Antoni A (b) and hypocellular Antoni B (c) areas. 